\title{
Aortic Medial Elastic Fiber Loss in Acute Ascending Aortic Dissection
}

\author{
William Clifford Roberts, MD ${ }^{\mathrm{a}, \mathrm{b}, \mathrm{c}, *}$, Travis James Vowels ${ }^{\mathrm{a}, \mathrm{g}}$, Benjamin Lee Kitchens ${ }^{\mathrm{h}}$, \\ Jong Mi Ko, BA ${ }^{\mathrm{a}}$, Giovanni Filardo, PhD, MPH ${ }^{\mathrm{e}, \mathrm{f}}$, Albert Carl Henry, MD ${ }^{\mathrm{d}}$, \\ Baron Lloyd Hamman, MD ${ }^{\mathrm{d}}$, Gregory John Matter, $\mathrm{MD}^{\mathrm{d}}$, and Robert Frederick Hebeler, Jr., MD ${ }^{\mathrm{d}}$
}

\begin{abstract}
The cause of acute aortic dissection continues to be debated. One school of thought suggests that underlying aortic medial cystic necrosis is the common denominator. The purpose of the present study was to determine if there was loss and, if so, how much loss of medial elastic fibers in the ascending aorta in patients with acute aortic dissection with the entrance tear in the ascending aorta. We examined operatively excised ascending aortas in 69 patients having acute dissection with tears in the ascending aorta. Patients with previous aortotomy, healed dissection, and connective tissue disorders were excluded. The 69 patients' ages ranged from 31 to 88 years (mean 56); 49 were men and 20 were women. Loss of aortic medial elastic fibers was graded as 0 (no loss), 1+ (trace), $2+$ (mild), 3+ (moderate), and $4+$ (full thickness loss). Of these 69 patients, $56(82 \%)$ had 0 or $1+$ elastic fiber loss; 13 patients (18\%), $2+$ to $4+$ loss including 4 with $2+, 6$ with $3+$, and 2 with $4+$. Nearly all patients $(97 \%)$ had a history of systemic hypertension and/or had received antihypertensive drug therapy. In conclusion, most patients (82\% in this study) having acute aortic dissection with entrance tears in the ascending aorta have normal numbers or only trace loss of aortic medial elastic fibers. Thus, underlying abnormal ascending aortic structure uncommonly precedes acute dissection. (C) 2011 Elsevier Inc. All rights reserved. (Am J Cardiol 2011;108:1639-1644)
\end{abstract}

Numerous publications have appeared in the last 50 years describing operative procedures and their results in patients having operative therapy for acute dissection involving the ascending aorta. ${ }^{1-10}$ Far fewer studies have been published on results of examination of the operatively resected portion of the ascending aorta. ${ }^{11-21}$ The present report focuses on aortic medial elastic-fiber structure in 69 patients having portions of the ascending aorta operatively resected because of acute dissection involving the ascending aorta with or without involvement of other portions of the aorta.

\section{Methods}

Surgical pathology files of the cardiovascular laboratory-a part of the pathology department of Baylor University Medical Center at Dallas-were searched for patients hav-

\footnotetext{
${ }^{a}$ Baylor Heart and Vascular Institute and ${ }^{b}$ Departments of Pathology, Internal Medicine ('Division of Cardiology), and ${ }^{\mathrm{d}}$ Cardiothoracic Surgery, Baylor University Medical Center, Dallas, Texas; ${ }^{\mathrm{C}}$ Institute for Health Care Research and Improvement, Baylor Health Care System and ${ }^{\mathrm{f}}$ Department of Statistical Science, Southern Methodist University, Dallas Texas; '

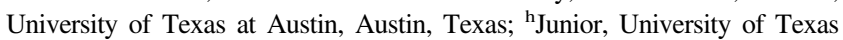
School of Medicine at San Antonio, Texas. Manuscript received September 9, 2011; revised manuscript received and accepted September 10, 2011.

The study was funded by Baylor Health Care System Foundation, Dallas, Texas.

*Corresponding author: Tel: 214-820-7911; fax: 214-820-7533.

E-mail address: wc.roberts@baylorhealth.edu (W.C. Roberts).
}

ing operatively resected portions of the ascending aorta with or without excision or repair of the aortic valve for acute dissection involving the ascending aorta with or without involvement of other portions of aorta. From May 1994 through June 2010, a period of 194 months (16.2 years), 119 specimens labeled as aortic dissection were received in the surgical pathology section and each was examined and described by 1 of us (W.C.R.). After the examination and description of the submitted specimen, histologic sections of all aortas were prepared: $\geq 1$ paraffin section was stained by the Movat method. ${ }^{22}$ All histologic sections were examined initially by W.C.R. to prepare the surgical pathology report and later, all together, as part of the present report. Total lengths (centimeters) of the sections of the aorta on each Movat-stained slide were measured and recorded.

Degree of loss of elastic fibers in the aortic media from examination of the Movat-stained slides was graded 0 to $4+$; grade 0 or $1+$ represented no loss or minimal loss or mild fragmentation of elastic fibers; grade 4 represented complete loss of elastic fibers in some full-thickness portions of media; grades 2 and 3 were intermediate (Figure 1).

Ascending aortas in 19 necropsy cases were selected to serve as controls for this study. None had cardiac valve disease or dilated ascending aortas. The 19 ranged in age from 28 to 82 years (mean 61); 10 were women and 9 were men. Twelve had died from cardiac causes (coronary artery disease events in 10, amyloidosis in 1, and lymphocytic myocarditis in 1) and 7 from noncardiac and nonvascular causes. Sections of ascending aorta perpendicular and parallel to the long axis were prepared from each control subject. In each of the 19 cases, 1 section was stained by hematoxylin and eosin, another by 


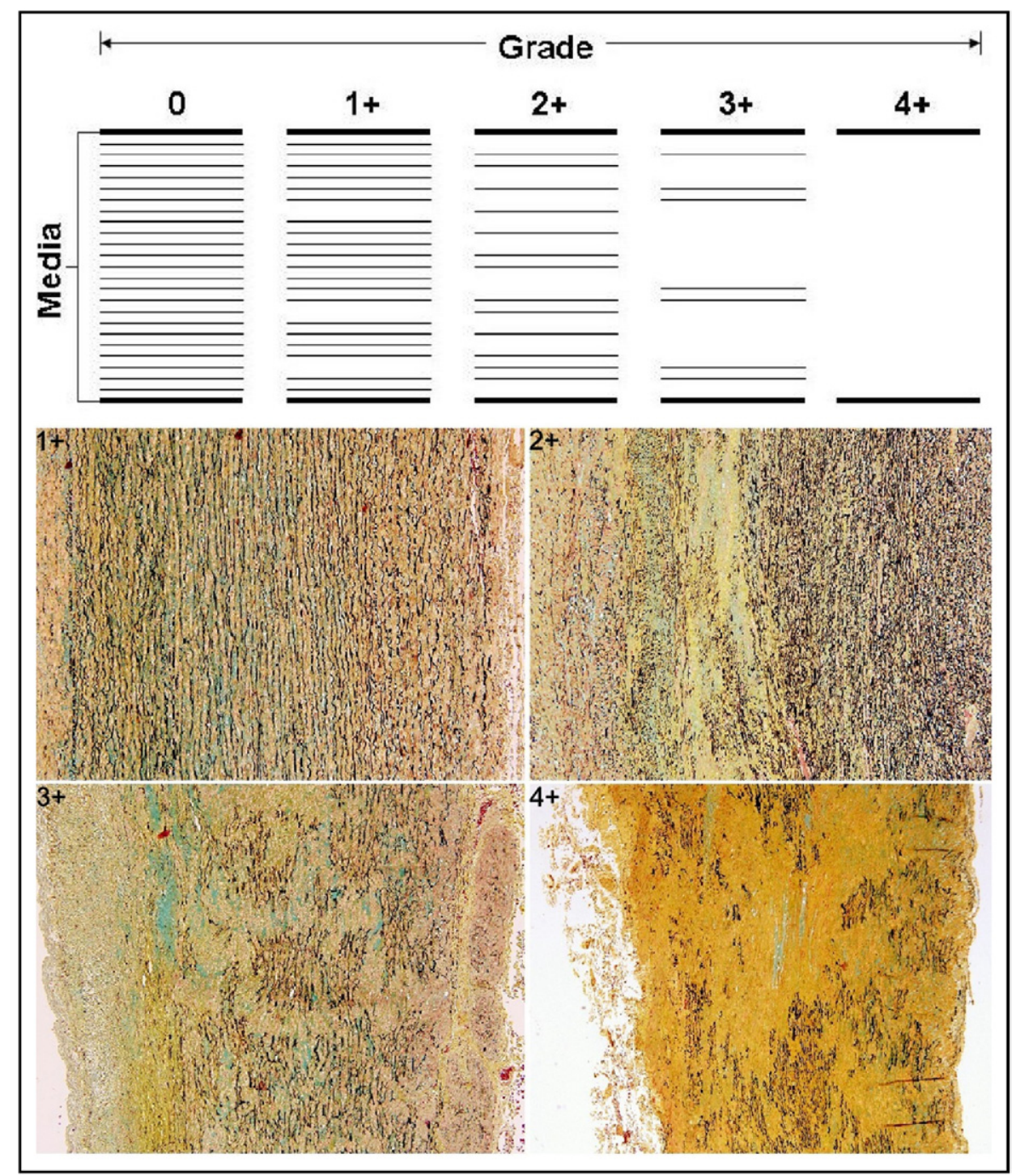

Figure 1. Diagram showing grading system used in this study. (Top) Diagram showing 0 to $4+$ loss of medial elastic fibers. The internal (top dark line) and external (bottom dark line) elastic membranes and elastic fibers in the media (lighter lines) are represented. (See text for explanation.) (Bottom) Photographs $(100 \times)$ and stained by Movat stain show medial elastic fiber loss 1+ (mid left) to 4+ (lower right). (Reproduced with permission from W.C. Roberts and the publisher of Circulation 2011;123:896-903.)

Movat stain, and another by elastic-van Gieson methods. Lengths of the aorta examined histologically were measured in centimeters.

Clinical records including admission note and/or discharge summary, echocardiographic and cardiac catheterization reports, and operative records were sought from all patients' medical charts and/or from the Baylor University Medical Center Apollo cardiovascular database (Apollo Advance C/S 4.2.13, LUMEDX Corp., Oakland, California).

Included in the present study were 69 patients who had resection of portions of the ascending aorta and initiating tears in the ascending aorta. Excluded from this study were 50 patients: 5 who had an acute aortic dissection in the operating room at the time of coronary artery bypass grafting or aortic valve replacement; 4 patients who had acute dissection involving the ascending aorta late postoperatively after coronary artery bypass grafting and/or aortic valve replacement; 6 patients who had a tear in the descending thoracic aorta (isthmic area) and acute retrograde dissection of the ascending aorta; and 35 patients who had healed (chronic) aortic dissection irrespective of the location of the initial aortic entrance site, including 20 patients who had a previous aortotomy of the ascending aorta. Also excluded were patients with genetically mediated conditions such as Marfan syndrome and Loeys-Dietz syndrome. None of the 69 patients included in the present study had a previous aortotomy, and all had dissection entrance sites in the ascending aorta and dissection afterward with operative resection of portions of the ascending aorta.

Descriptive statistics (percentage, mean $\pm \mathrm{SD}$ ) were used to describe patients included in the study. A Cox proportional hazards model (without covariates) was used to assess the unadjusted association of loss of medial elastic fibers $(2+, 3+$, or $4+$ ) and mortality. Unadjusted survival curves and survival estimates were computed using the Kaplan-Meier method.

This study was approved by the institutional review board at Baylor University Medical Center. 
Table 1

Characteristics of patients with acute aortic dissection with tears in ascending aorta

\begin{tabular}{|c|c|c|c|}
\hline Variable & \multicolumn{2}{|c|}{ Elastic Fiber Loss } & $\mathrm{p}$ Value* \\
\hline \multirow{2}{*}{ Men } & $38(68 \%)$ & $11(85 \%)$ & $0.234^{\dagger}$ \\
\hline & $31-77(56 \pm 13)[56]$ & $34-66(44 \pm 9)[44]$ & \\
\hline Women & $18(32 \%)$ & $2(15 \%)$ & \\
\hline White & $34(61 \%)$ & $10(77 \%)$ & \\
\hline Black & $14(25 \%)$ & $3(23 \%)$ & \\
\hline Hispanic & $4(7 \%)$ & 0 & \\
\hline Other or unclear & $4(7 \%)$ & 0 & \\
\hline Systemic hypertension by history or antihypertension therapy & $51(91 \%)$ & $13(100 \%)$ & 0.268 \\
\hline Previous resection, abdominal aortic aneurysm & $3(5 \%)$ & 0 & 0.397 \\
\hline$>30$ & $12(34 \%)$ & $4(40 \%)$ & \\
\hline Women & $18.9-44.7(27.1 \pm 6.4)[26.8]$ & $21,26.6$ & \\
\hline$\leq 25$ & $7(41 \%)$ & $1(50 \%)$ & \\
\hline $26-30$ & $6(35 \%)$ & $1(50 \%)$ & \\
\hline$>30$ & $4(24 \%)$ & 0 & \\
\hline Aortic valve $(\mathrm{n}=49)$ & & & 0.797 \\
\hline Replaced & $20(54 \%)$ & $7(58 \%)$ & \\
\hline "Repaired" & $17(45 \%)$ & $5(41 \%)$ & \\
\hline Number aortic valve cusps $(\mathrm{n}=56)$ & & & 0.3559 \\
\hline 2 & $3(7 \%)$ & $2(15 \%)$ & \\
\hline 3 & $40(93 \%)$ & $11(85 \%)$ & \\
\hline Weight $(\mathrm{g})$ of excised aortic valves $(\mathrm{n}=17)$ & $0.38-1.75(0.77 \pm 0.43)[0.67]$ & $0.39-0.93(0.68 \pm 0.20)[0.69]$ & 0.675 \\
\hline Women & $6-16(11 \pm 3)[12]$ & 8,17 & 0.824 \\
\hline Intimal plaque, ascending aorta & $7(13 \%)$ & $2(15 \%)$ & 0.785 \\
\hline Died: days after operation $(n=30)$ & & & 0.115 \\
\hline$\leq 30$ & $19(79 \%)$ & $3(50 \%)$ & \\
\hline & $0-28(5 \pm 7)[3]$ & $2,8,13$ & \\
\hline$>30$ & $5(21 \%)$ & $3(50 \%)$ & \\
\hline & $58-2,418(712 \pm 1,004)[141]$ & $150,445,2,060$ & \\
\hline Days in hospital postoperatively in patients living $>30$ days & $4-48(14 \pm 11)[10]$ & $5-63(16 \pm 18)[10]$ & 0.548 \\
\hline
\end{tabular}

* The $\mathrm{p}$ values accounted for multiple comparisons.

$\dagger$ The $\mathrm{p}$ value accounts for gender versus elastic fiber loss comparison.

$¥$ One of the 7 patients had bypass because of coronary artery disease; the other 6 had bypass because the dissection or tear involved the left and/or right coronary ostia.

\section{Results}

Findings in the 69 patients are presented in Table 1. Qualitative comparison of degree of loss of medial elastic fibers at the initial examination of the Movat-stained sections to the re-examination of the Movat-stained sections showed only minimal discrepancies: some cases called normal at the initial examination were occasionally called $1+$ on re-examination or vice-versa; sections classified as $2+$ or $3+$ or $4+$ initially were classified similarly on re-examination. Photomicrographs of typical acute dissection are shown in Figure 2.
Examination of Movat-stained and elastic-van Giesonstained sections of aorta in the 19 control subjects disclosed no discrepancies in degree of medial elastic fiber loss or lack thereof between the 2 stains in any subject. Degree of elastic fiber loss in all 19 control subjects was zero or $1+$. Specifically, no subject had $2+, 3+$, or $4+$ elastic fiber loss. Lengths of ascending aorta examined from the Movatstained sections ranged from 4 to $16 \mathrm{~cm}$ (mean 10).

At the time of the operation the mean age of the 49 men was 53 years and that of the 20 women was 64 years (Table 


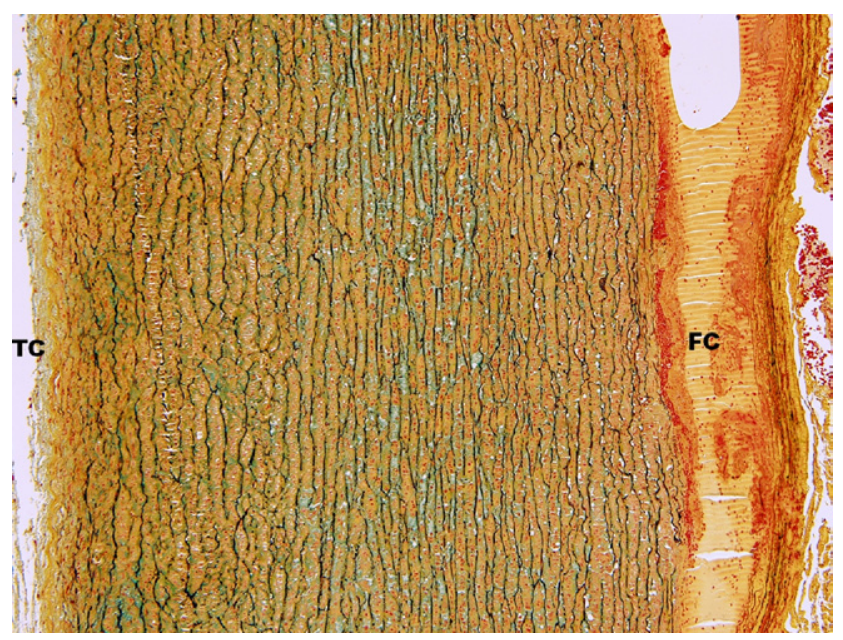

Figure 2. Photomicrograph of a typical aortic dissection in a 57-year-old man. The tear was in the ascending aorta and the dissection traveled retrograde into the aorta behind the sinuses of Valsalva and anterograde to the common iliac arteries. The true lumen (TC) (left) and the false channel (FC) (right) are visible. The dissection is located in the very outer media. The black-staining medial elastic fibers are few in number in the outer wall of the false channel. Because the outer wall is so much thinner than the partition of media between the true lumen and false channel, rupture exteriorly is very common but rupture of the false channel back into the true lumen is very rare. Medial elastic fiber loss in this patient was graded $1+/ 4+($ Movat stain, $100 \times)$.

1). Nearly $2 / 3$ were white. Thirty of the 69 patients $(43 \%)$ have died: $22(32 \%)$ within 30 days of the operative procedure and $8(12 \%)>30$ days later. Of the 47 surviving $>30$ days, stay in the hospital after operation ranged from 4 to 63 days (mean 15, median 10). By history, $92 \%$ of patients (59 of 64) had systemic hypertension, 70\% (40/57) were on antihypertensive therapy, and $97 \%$ (64/66) had a history of hypertension or were on antihypertensive therapy. Body mass indexes (BMIs; kilograms per square meter) ranged from 18.9 to 46.4 (mean 29.0, median 27.7) and 20 of 64 patients $(31 \%)$ had BMI $<25 \mathrm{~kg} / \mathrm{m}^{2}$. Only 1 of the 69 patients was documented to have atherosclerotic coronary artery narrowing. Seven patients, however, had coronary bypass, 6 because of dissection or tears involving the origin of the right ( 5 patients) or left main (1 patient) coronary artery. The aortic valve was replaced in 27 patients $(39 \%)$ and "repaired" in another 22 patients (32\%). At least 5 patients were described at operation or by the surgical pathologist (W.C.R.) as having congenitally bicuspid aortic valves. The operatively excised 3-cuspid valves (13 patients) weighed 0.38 to $0.93 \mathrm{~g}$ (mean 0.62 ), and the congenitally bicuspid valves (4 patients) weighed from 0.53 to $1.75 \mathrm{~g}$ (mean 1.14). The aortic valve was replaced with a bioprosthesis in 3 patients, a mechanical prosthesis in 19, and a homograft in 5 patients (Table 2).

Operatively excised aortas ranged in weight from 0.4 to $59 \mathrm{~g}$ (mean 17, median 14) and in 50 patients $(76 \%$ ) weighed $>10 \mathrm{~g}$. Lengths of ascending aorta examined in the Movat-stained slides (those stained for elastic fibers) ranged from 4 to $21 \mathrm{~cm}$ (mean 11, median 12). Losses of elastic fibers in the media of sections of ascending aorta were 0 (24 patients, 35\%), 1+ (32 patients, 46\%), 2+ (5 patients, 7\%), $3+(6$ patients, $9 \%)$, and $4+(2$ patients, $3 \%)$. Atheroscle- rotic plaques were present in the ascending aorta in 9 patients $(13 \%)$. Of the 5 patients with bicuspid aortic valves, aortic medial elastic fiber loss was 0 in $1,1+$ in 2 , and $3+$ in 2. A typical example of aortic dissection is shown in Figure 2.

Unadjusted association between loss of medial elastic fibers and mortality was not significant (hazard ratio 0.95 , $95 \%$ confidence interval 0.39 to $2.34, \log$-rank $p=0.91$ ). Survival curves are shown in Figure 3. Survival was assessed by the Social Security Death Index.

\section{Discussion}

The present study focused on 69 patients who had acute aortic dissection with entrance tears in the ascending aorta and operative resection of a portion of ascending aorta with or without replacement or repair of the native aortic valve. The purpose was to determine if the elastic fiber structure of the media of the ascending aorta was normal or abnormal. Examination of 4 to $21 \mathrm{~cm}$ (mean 12) of aorta stained for elastic fibers (Movat stain) showed that 56 of the 69 patients $(81 \%)$ had normal or nearly normal numbers of medial elastic fibers and that only $13(19 \%)$ had focal loss $(2+$ to $4+$ ) of medial elastic fibers. The $2+$ to $4+$ losses of elastic fibers are considered changes greater than that expected by aging alone. ${ }^{13}$

Why did the study of histologic sections of ascending aorta focus only on medial elastic fibers when the wall of the ascending aorta also contains smooth muscle cells, collagen, and some mucoid material? The reason is that examination of the elastic fiber structure is easily discernible and interpretation is highly reproducible. Grading of degree of medial elastic fiber loss when examined initially (when preparing the surgical pathology report) and then again altogether when re-examining sections for the present study showed no discordant interpretations. A few patients considered to have 0 elastic fiber loss initially were graded $1+$ on re-examination and vice-versa; all cases graded $2+, 3+$, or $4+$ initially were graded similarly on re-examination. When medial elastic fibers are lost, it appears they are replaced by fibrous tissue and by small deposits of mucoid material, suggesting that medial elastic fibers serve as a good marker of other changes in the aortic media.

The phrases "idiopathic cystic medionecrosis," "cystic medionecrosis," or simply "medionecrosis" were first used by Erdheim ${ }^{23,24}$ in 1929 and subsequently have often been used to describe aortic medial histologic lesions in patients with acute aortic dissection. Indeed, there is a widely held perception that medial cystic necrosis is the chief predisposing cause of acute aortic dissection. However, as pointed out by Hirst and Gore, ${ }^{12}$ Erdheim studied only 2 patients, describing the aorta histologically in meticulous detail, but each of his 2 patients had rupture of a nondissecting aneurysm of the ascending aorta, not aortic dissection!

Erdheim's terms, as pointed out by Hirst and Gore, ${ }^{12}$ Schlatmann and Becker, ${ }^{13}$ and Roberts, ${ }^{17}$ are not ideal because the terms are inappropriate: "cystic" refers to cysts, which are generally considered to have true linings (not so in the aortic media); "necrosis" is extremely difficult to determine but almost surely is the result, when it occurs, of intraluminal arterial pressure compressing the adjacent me- 
Table 2

Mortality rate of patients having operative treatment for acute ascending aortic dissection with or without concomitant aortic valve replacement or repair

\begin{tabular}{|c|c|c|c|c|c|c|c|}
\hline \multirow{2}{*}{$\begin{array}{l}\text { Died } \\
\text { Postoperatively }\end{array}$} & \multicolumn{4}{|c|}{ Concomitant AVR Using } & \multirow[b]{2}{*}{$\begin{array}{c}\text { Concomitant AV } \\
\text { Repair } \\
(\mathrm{n}=22)\end{array}$} & \multirow[b]{2}{*}{$\begin{array}{c}\text { Without AVR or } \\
\text { Repair } \\
(\mathrm{n}=20)\end{array}$} & \multirow[b]{2}{*}{$\begin{array}{c}\text { Total } \\
(\mathrm{n}=69)\end{array}$} \\
\hline & $\begin{array}{c}\text { Mechanical } \\
\text { Prosthesis } \\
(\mathrm{n}=19)\end{array}$ & $\begin{array}{l}\text { Bioprosthesis } \\
\qquad(\mathrm{n}=3)\end{array}$ & $\begin{array}{l}\text { Homograft } \\
\qquad(\mathrm{n}=5)\end{array}$ & $\begin{array}{l}\text { Any Type of } \\
\text { Substitute Valve } \\
\quad(\mathrm{n}=27)\end{array}$ & & & \\
\hline$\leq 30$ days & 5 & 2 & 3 & 10 & 5 & 7 & $22(32 \%)$ \\
\hline$>30$ days & 3 & 0 & 1 & 4 & 2 & 2 & $8(12 \%)$ \\
\hline Total & $8(42 \%)$ & $2(67 \%)$ & $4(80 \%)$ & $14(52 \%)$ & $7(32 \%)$ & $9(45 \%)$ & $30(44 \%)$ \\
\hline
\end{tabular}

$\mathrm{AV}=$ aortic valve; $\mathrm{AVR}=$ aortic valve replacement.

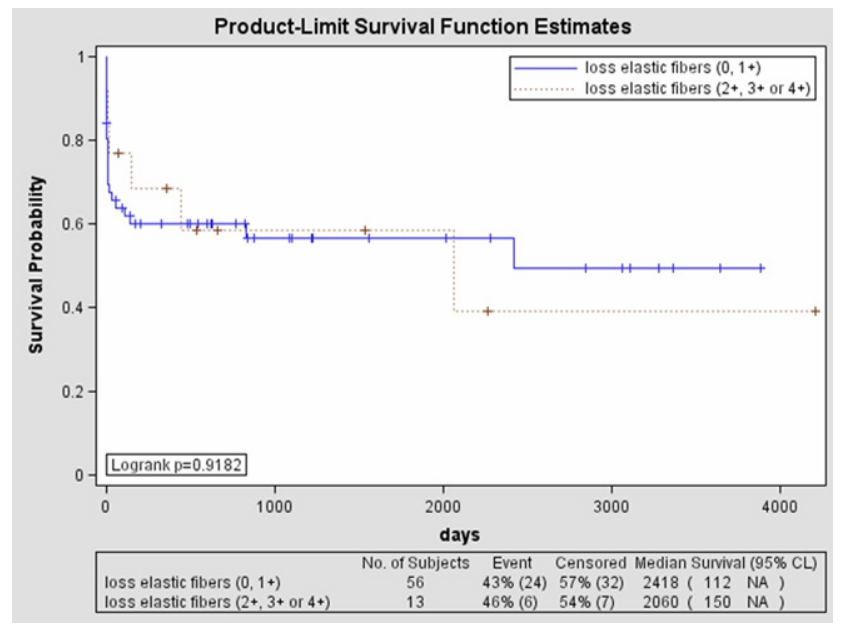

Figure 3. Unadjusted (Kaplan-Meier) curves depicting long-term survival by loss of medial elastic fiber. $\mathrm{CL}=$ confidence limit; $\mathrm{NA}=$ not available.

dia-something occurring after, not before, acute dissection. We believe that focusing on medial elastic fibers alone provides the most accurate and reproducible description of the aortic media in patients with acute aortic dissection, and that the phrase "cystic medionecrosis," as emphasized by Schlatmann and Becker, ${ }^{14}$ should be abandoned and no longer used to indicate a pathologic condition that underlies acute aortic dissection.

A near universal finding in our 69 patients was systemic hypertension: by history in $92 \%$ (59/64), by antihypertensive therapy in $70 \%$ (40/57), and by history and/or antihypertensive therapy in $97 \%$ (64/66). Many others, of course, have emphasized the frequency of systemic hypertension in patients with acute aortic dissection. ${ }^{25-29}$ Frequency of systemic hypertension increases as body weight increases ${ }^{30}$ : $73 \%$ of the men $(33 / 45)$ had BMI $>25 \mathrm{~kg} / \mathrm{m}^{2}$, including $36 \%$ whose BMI was $>30 \mathrm{~kg} / \mathrm{m}^{2} ; 58 \%$ of the women $(11 / 19)$ had BMI $>25 \mathrm{~kg} / \mathrm{m}^{2}$, including $21 \%$ whose BMI was $>30 \mathrm{~kg} / \mathrm{m}^{2}$. African-Americans have a higher frequency of systemic hypertension than do European-Americans $^{31}$ : there was a larger percentage of African-Americans in our study than are present in the general population ( $25 \%$ vs $13 \%$ ). Certain activities that cause a sudden increase in systemic arterial pressure have precipitated acute aortic dissection, e.g., cocaine inhalation. ${ }^{32}$ As pointed out by Carlson et al, ${ }^{33}$ the incidence of cystic medial necrosis (basophilic discoloration of hematoxylin-eosin stains, medial cysts, elastic fiber interruption with or without "retraction") of the ascending aorta is higher in hypertensive than normotensive subjects of comparable ages.

Patients with congenitally bicuspid aortic valves have a higher frequency of aortic dissection with tears in the ascending aorta than do patients with tricuspid aortic valves ${ }^{34}$ : $\geq 9 \%$ of our patients $(5 / 56)$ had congenitally bicuspid valves: loss of medial elastic fibers in them was 0 in $1,1+$ in 2 , and $3+$ in 2 patients. The bicuspid valves were heavier than the tricuspid valves (mean 1.14 vs $0.62 \mathrm{~g}$ ).

Acute aortic dissection generally occurs in patients younger than those with acute coronary syndrome. ${ }^{25-29}$ In 1 large study the average age of death in men from coronary heart disease not treated by revascularization was 61 years and that in women was 71 years. $^{35}$ In contrast, in our 69 dissection patients, mean age at operation in the 49 men was 53 years and that in the 20 women was 64 years. Had not the operative procedure been performed, death almost certainly would have rapidly followed.

Atherosclerosis appears to be unrelated to acute aortic dissection. $^{36}$ Only 9 of our patients had atherosclerotic plaques in the ascending aorta and in each the plaques were small. In addition, atherosclerotic narrowing of $\geq 1$ major coronary artery was documented in only 1 of our 69 patients.

The positive features of the present study are the following: (1) all histologic sections were examined and medial elastic fiber loss graded initially for the surgical pathology report and later all together by the same investigator (W.C.R.); (2) lengths of the ascending aorta examined histologically were recorded for the first time in dissection patients; (3) reproducibility of the histologic grading system was nearly $100 \%$; (4) weights of resected portions of dissected ascending aorta were recorded for the first time; (5) weights of operatively excised valves were recorded; (6) data on BMI were recorded; and (7) a relatively long follow-up after operative treatment was available.

The present study has limitations: (1) although preoperative computed tomography was performed in many patients $(65 \%)$, most were performed at the referring hospital and the results-other than the presence of aortic dissection-of most are not known to us; (2) different quantities of aorta were available for examination, although $\geq 4 \mathrm{~cm}$ of aorta was examined histologically in all patients; and (3) aortic valve structure (unicuspid, bicuspid, tricuspid) was not known in $19 \%$ of patients (it was known in $81 \%$ of patients.). 
1. Fann JI, Smith JA, Miller DC, Mitchell RS, Moore KA, Grunkemeier G, Stinson EB, Oyer PE, Reitz BA, Shumway NE. Surgical management of aortic dissection during a 30-year period. Circulation 1995; 92:113-121.

2. Von Segesser LK, Lorenzetti E, Lachat M, Niederhäuser U, Schönbeck M, Vogt PR, Turina MI. Aortic valve preservation in acute type A dissection: is it sound? J Thorac Cardiovasc Surg 1996; 111: 381-391.

3. Bachet J, Goudot B, Dreyfus GD, Brodaty D, Dubois C, Delentdecker P, Guilmet D. Surgery for acute type A aortic dissection: the hospital Foch experience (1977-1998). Ann Thorac Surg 1999; 67: 20062009.

4. David TE, Armstron S, Ivanov J, Barnard S. Surgery for acute type A aortic dissection. Ann Thorac Surg 1999; 67: 1999-2001.

5. Leyh RG, Schmidtke C, Bartels C, Sievers HH. Valve-sparing aortic root replacement (remodeling/reimplantation) in acute type A dissection. Ann Thorac Surg 2000; 70: 21-24.

6. Sabik JF, Lytle BW, Blackstone EH, McCarthy PM, Loop FD, Cosgrove DM. Long-term effectiveness of operations for ascending aortic dissections. J Thorac Cardiovasc Surg 2000; 119: 946-962.

7. Westaby S, Saito S, Katsumata T. Acute type A dissection: conservative methods provide consistently low mortality. Ann Thorac Surg 2002; 73: 707-713.

8. Elefteriades JA. Natural history of thoracic aortic aneurysms: indications for surgery, and surgical versus nonsurgical risks. Ann Thorac Surg 2002; 74: 1877-1880.

9. Lai DT, Robbins RC, Mitchell RS, Moore KA, Oyer PE, Shumway NE, Reitz BA, Miller DC. Does profound hypothermic circulatory arrest improve survival in patients with acute type A aortic dissection? Circulation 2002;106:218-228.

10. Tan ME, Morshuis WJ, Dossche KM, Kelder JC, Waanders FG, Schepens MA. Long-term results after 27 years of surgical treatment of acute type A aortic dissection. Ann Thorac Surg 2005; 80: 523-529.

11. Gore I, Seiwert VJ. Dissecting aneurysm of the aorta; pathological aspects; an analysis of eighty-five fatal cases. AMA Arch Pathol 1952; 53: $121-141$.

12. Hirst AE, Gore I. Editorial: Is cystic medionecrosis the cause of dissecting aortic aneurysm? Circulation 1976; 53: 915-916.

13. Schlatmann TJ, Becker AE. Histologic changes in the normal aging aorta: implications for dissecting aortic aneurysm. Am J Cardiol 1977; 39: $13-20$.

14. Schlatmann TJM, Becker AE. Pathogenesis of dissecting aneurysm of aorta. Comparative histopathologic study of significance of medial changes. Am J Cardiol 1977; 39: 21-26.

15. Kunita Y. A pathological study of dissecting aneurysm in individuals under forty years of age including a case of a 13 years old boy. Acta Pathol Jpn 1978; 28: 253-263.

16. Leonard JC, Hasleton PS. Dissecting aortic aneurysm: a clinicopathological study. Q J Med 1979;189:55-76.

17. Roberts WC. Aortic dissection: anatomy, consequences, and causes. Am Heart J 1981;101:195-214.

18. Larson EW, Edwards WD. Risk factors for aortic dissection: a necropsy study of 161 cases. Am J Cardiol 1984; 53: 849-855.

19. Lindsay J Jr, Hurst JW. Clinical features and prognosis in dissecting aneurysm of the aorta. A re-appraisal. Circulation 1967; 35: 880-888.

20. McManus BM, Cassling RS, Soundy TJ, Wilson JE, Sears TD, Rogler WC, Buehler BA, Wolford JF, Duggan MJ, Byers PH, Fleming WH, Sanger WG. Familial aortic dissection in the absence of ascending aortic aneurysms: a lethal syndrome associated with precocious systemic hypertension. Am J Cardiovasc Pathol 1986;1:55-67.

21. Mészáros I, Mórocz J, Szlávi J, Schmidt J, Tornóci L, Nagy L, Szép L. Epidemiology and clinicopathology of aortic dissection. Chest 2000; 117: 1271-1278.

22. Movat HZ. Demonstration of all connective tissue elements in a single section; pentachrome stains. AMA Arch Pathol 1955; 60 :289-295.

23. Erdheim J. Medionecrosis aortae idiopathica. Virchows Arch Pathol Anat 1929; 273: 454-479.

24. Erdheim J. Medionecrosis aortae idiopathica cystica. Virchows Arch Pathol Anat 1930; 276: 187-229.

25. Spittell PC, Spittell JA, Joyce JW, Tajik AJ, Edwards WD, Schaff HV, Stanson AW. Clinical features and differential diagnosis of aortic dissection: experience with 236 cases (1980 through 1990). Mayo Clin Proc 1993; 68: 642-651.

26. Hagan PG, Nienaber CA, Isselbacher EM, Bruckman D, Karavite DJ, Russman PL, Evangelista A, Fattori R, Suzuki T, Oh JK, Moore AG, Malouf JF, Pape LA, Gaca C, Sechtem U, Lenferink S, Deutsch HJ, Diedrichs H, Marcos y Robles J, Llovet A, Gilon D, Das SK, Armstrong WF, Deeb GM, Eagle KA. The International Registry of Acute Aortic Dissection (IRAD): new insights into an old disease. JAMA 2000; 283: 897-903.

27. Januzzi JL, Isselbacher EM, Fattori R, Cooper JV, Smith DE, Fang J, Eagle KA, Mehta RH, Nienaber CA, Pape LA; International Registry of Aortic Dissection (IRAD). Characterizing the young patient with aortic dissection: results from the international registry of aortic dissection (IRAD). J Am Coll Cardiol 2004; 43: 665-669.

28. Clouse WD, Hallett JW, Schaff HV, Spittell PC, Rowland CM, Ilstrup DM, Melton LJ. Acute aortic dissection: population-based incidence compared with degenerative aortic aneurysm rupture. Mayo Clin Proc 2004;79:176-180.

29. Olsson C, Thelin S, Ståhle E, Ekbom A, Granath F. Thoracic aortic aneurysm and dissection: increasing prevalence and improved outcomes reported in a nationwide population-based study of more than 14,000 cases from 1987 to 2002. Circulation 2006; 114: 2611-2618.

30. Wilson PW, D'Agostino RB, Sullivan L, Parise H, Kannel WB. Overweight and obesity as determinants of cardiovascular risk: the Framingham experience. Arch Intern Med 2002; 162: 1867-1872.

31. Morris RC Jr, Sebastian A, Forman A, Tanaka M, SchmidlinO. Normotensive salt sensitivity: effects of race and dietary potassium. $\mathrm{Hy}$ pertension 1999; 33: 18-23.

32. Barth CW III, Bray M, Roberts WC. Rupture of the ascending aorta during cocaine intoxication. Am J Cardiol 1986; 57: 496.

33. Carlson RG, Lillehei CW, Edwards JE. Cystic medial necrosis of the ascending aorta in relation to age and hypertension. Am J Cardiol 1970; 25: 411-415.

34. Roberts CS, Roberts WC. Dissection of the aorta associated with congenital malformation of the aortic valve. J Am Coll Cardiol 1991; 17: 712-716.

35. Roberts WC, Potkin BN, Solus DE, Reddy G. Mode of death, frequency of healed and acute myocardial infarction, number of major epicardial coronary arteries severely narrowed by atherosclerotic plaque, and heart weight in fatal atherosclerotic coronary artery disease: analysis of 889 patients studied at necropsy. J Am Coll Cardiol 1990; 15: 196-203.

36. Achneck H, Modi B, Shaw C, Rizzo J, Albornoz G, Fusco D, Elefteriades J. Ascending thoracic aneurysms are associated with decreased systemic atherosclerosis. Chest 2005;128:1580-1586. 